\title{
Casticin, a flavonoid, potentiates TRAIL-induced apoptosis through modulation of anti-apoptotic proteins and death receptor 5 in colon cancer cells
}

\author{
SAN-YUAN TANG ${ }^{1}$, MEI-ZUO ZHONG ${ }^{2}$, GUANG-JIN YUAN ${ }^{3}$, SU-PING HOU ${ }^{4}$, \\ LEI-LAN YIN $^{1}$, HAO JIANG ${ }^{1}$ and ZHENG-YANG YU ${ }^{1}$
}

\begin{abstract}
${ }^{1}$ Department of Medical Oncology, The First Affiliated Hospital of South China University, Hengyang, Hunan 421001; ${ }^{2}$ Department of Medical Oncology, Xiangya Hospital of Central South University, Changsha, Hunan 410008; ${ }^{3}$ Cancer Center, The 82nd Hospital of the Chinese People's Liberation Army, Huai'an, Jiangsu 223001;

${ }^{4}$ Department of Medical Oncology, Harrison International Peace Hospital, Hengshui, Hebei 053000, P.R. China
\end{abstract}

Received August 8, 2012; Accepted October 17, 2012

DOI: $10.3892 /$ or.2012.2127

\begin{abstract}
We investigated the effect of casticin on apoptosis induced by tumor necrosis factor (TNF)-related apoptosisinducing ligand (TRAIL). We found that casticin potentiated TRAIL-induced apoptosis in human colon cancer cells. Casticin downregulated cell survival proteins including Bcl-xL, Bcl-2, survivin, XIAP and cFLIP, and induced death receptor 5 (DR5), but had no effect on DR4 and decoy receptors (DcR1 or DcR2). Deletion of DR5 by siRNA significantly reduced the apoptosis induced by TRAIL and casticin. In addition, casticin induced reactive oxygen species (ROS) generation in a dose-dependent manner. Collectively, the present study showed that casticin potentiates TRAIL-induced apoptosis through downregulation of cell survival proteins and induction of DR5 mediated by ROS.
\end{abstract}

\section{Introduction}

Tumor necrosis factor (TNF)-related apoptosis-inducing ligand (TRAIL) is a member of the TNF superfamily, and has a strong antitumor activity in a wide range of cancer cell types with minimal cytotoxity to most normal cells and tissues (1). TRAIL induces cell apoptosis by interacting with cell-surface receptors, five of which have been discovered thus far, including the two agonistic receptors, death receptor (DR)4 and DR5, and the three antagonistic decoy receptors, DcR1, DcR2 and osteoprotegerin $(2,3)$. DR4 and DR5 contain a cytoplasmic region designated as the 'death domain' (DD), and, following ligation of TRAIL, they recruit and activate an adaptor protein known

Correspondence to: Dr San-Yuan Tang, Department of Medical Oncology, The First Affiliated Hospital of South China University, Hengyang, Hunan 421001, P.R. China

E-mail: tsy09@126.com

Key words: casticin, apoptosis, cell-surface receptor, tumor necrosis factor-related apoptosis-inducing ligand, colon cancer as Fas-associated death domain (FADD) through interactions between the DD on them and FADD. FADD, in turn, recruits and activates caspase- 8 via its death effector domain (DED), leading to the formation of the death-inducing signaling complex (DISC). Activation of caspase- 8 subsequently initiates proteolytic activation of downstream effector caspases such as caspase-3, -6 and -7 and finally induces apoptosis. Alternatively, caspase- 8 can also trigger a mitochondria-dependent apoptotic amplification loop by activating Bid, which induces the release of cytochrome $c$ from mitochondria, the activation of caspase-9, caspase-3, caspase-7 and finally apoptosis (4). Recent studies have shown that a number of cancer cells are resistant to apoptosis induction by TRAIL (5). The mechanisms involved in TRAIL resistance include the loss of DR4 or DR5, upregulation of decoy receptors, alternations in expression of proteins that affect caspase activation (inactivation of pro-apoptotic molecules: Bax, Bak, Bad, Bim or Bid; overexpression of anti-apoptotic molecules: survivin, cFLIP, FAP-1, Bcl-2, Bcl-xL) (5-7). However, TRAIL-resistant cancer cells can be sensitized by combined treatment with chemotherapeutic drugs and TRAIL (8-11), suggesting that TRAIL resistance may be overcome by combination treatment, which may be a promising novel approach in cancer therapy.

Casticin, a flavonoid isolated from Vitex rotundifolia, is widely used as an anti-inflammatory agent in Chinese traditional medicine. Recent studies have shown that casticin has a wide range of actions, including anti-oxidant, anti-inflammatory, immunomodulatory, pro-apoptotic and anti-proliferative properties, and has antitumor activity in a variety of cancers, including breast, lung and colon cancer and leukemia (12-18). Yang et al recently reported that casticin induces apoptosis of hepatocellular carcinoma cells and the mechanisms involve depletion of intracellular glutathione content and upregulation of DR5 (19). In the present study, we investigated whether casticin can potentiate TRAIL-induced apoptosis and its mechanisms. We found that casticin can indeed enhance TRAIL-induced apoptosis through downregulation of cell survival proteins and upregulation of DR5 mediated by reactive oxygen species (ROS). 


\section{Materials and methods}

Drugs and reagents. Casticin was purchased from Chengdu Biopurify Phytochemicals Ltd., (Chengdu, China), and was prepared in dimethylsulfoxide (DMSO) at a concentration of $10 \mathrm{mmol} / 1$ and aliquots were stored at $-80^{\circ} \mathrm{C}$. Soluble recombinant human TRAIL was purchased from PeproTech (Rocky Hill, NJ, USA). DMEM medium and fetal bovine serum (FBS) were obtained from Invitrogen; Tris, glycine, $\mathrm{NaCl}$, SDS, bovine serum albumin, $\mathrm{N}$-acetylcysteine, fluorouracil (5-FU), paclitaxel (TAX), and antibodies against TRAF1 and $\beta$-actin were from Sigma. 2',7'-dichlorofluorescein diacetate (DCFH-DA) was purchased from Molecular Probes Inc.; antibody against DR5 from ProSci Inc.; anti-XIAP antibody from Cell Signaling Technology (Danvers, MA, USA). Antibodies against DR4, poly(ADP-ribose) polymerase (PARP), Bcl-2, Bcl-xL, Bax, Bid, survivin and caspase-3 were obtained from Santa Cruz Biotechnology.

Cell lines. Human colon cancer HT-29, HCT-116, SW480 cell lines were purchased from the American Type Culture Collection. Cells were cultured in DMEM with 10\% FBS, $100 \mathrm{U} / \mathrm{ml}$ penicillin and $100 \mathrm{mg} / \mathrm{ml}$ streptomycin.

MTT assay. Cells were seeded in a 96-well plate at a density of $0.5 \times 10^{4}$ cells/well and incubated for $24 \mathrm{~h}$, followed by treatment with various concentrations of casticin and TRAIL alone or in combination for 24 h. 3-[4,5-dimethylthiazol2-yl]-2,5 diphenyl tetrazolium bromide (MTT) colorimetric analysis was performed as described by Cao et al (20). The $\mathrm{IC}_{50}$ value, at which $50 \%$ of the cell growth inhibition compared with DMSO control, was calculated by nonlinear regression analysis using GraphPad Prism software (San Diego, CA, USA).

Apoptosis detection by morphological observation following $A O / E B$ staining. Cells were treated with various concentrations of casticin and TRAIL alone or in combination for $24 \mathrm{~h}$, and then harvested with $0.25 \%$ trypsin and resuspended in DMEM medium. After staining for $10 \mathrm{~min}$ with $4 \mathrm{ml}$ of an $\mathrm{AO}$ $(100 \mathrm{mg} / \mathrm{ml}) / \mathrm{EB}(100 \mathrm{mg} / \mathrm{ml})$ dye mixture, cells were visualized immediately under a fluorescence microscope. Specific apoptotic cell death was calculated as (percentage of experimental apoptosis - percentage of spontaneous apoptosis)/(100 - percentage of spontaneous apoptosis) x 100 .

Flow cytometry using propidium iodide (PI) staining. Cells were seeded at a density of $4 \times 10^{6}$ cells $/ \mathrm{ml}$ in $100 \mathrm{ml}$ culture flasks for $24 \mathrm{~h}$ and then treated with the medium containing various concentrations of casticin or TRAIL or both for the indicated times. PI staining for DNA content analysis was performed as described by Yang et al (21).

Analysis of cell-surface expressions of DR4 and DR5. Cells were treated with $3 \mu \mathrm{mol} / \mathrm{l}$ casticin for $24 \mathrm{~h}$, and then stained with phycoerythrin-conjugated mouse anti-human DR4 or DR5 monoclonal antibody (R\&D Systems) for $45 \mathrm{~min}$ at $4^{\circ} \mathrm{C}$ according to the manufacturer's instructions. The cells were then resuspended and analyzed by flow cytometry with phycoerythrin-conjugated mouse $\mathrm{IgG} 2 \mathrm{~B}$ as an isotype control.
Determination of ROS. Intracellular ROS accumulation was measured by flow cytometry using the fluorescent probe DCFH-DA. Cells were incubated with $10 \mu \mathrm{mol} / 1$ of DCFH-DA for $30 \mathrm{~min}$ at $37^{\circ} \mathrm{C}$ in the dark. Following incubation, the cells were washed with PBS and analyzed within 30 min using FACScan (Becton-Dickinson, San Jose, CA, USA) equipped with an air-cooled argon laser tuned to $488 \mathrm{~nm}$. The specific fluorescence signals corresponding to DCFH-DA were collected with a $525-\mathrm{nm}$ band pass filter. As a rule, $10^{4}$ cells were counted in each determination.

Western blot analysis. Total cell extracts were obtained as described by Yang et al (21). Cell lysate containing $50 \mu \mathrm{g}$ of protein was separated on 7.5-12\% SDS-polyacrylamide gel for electrophoresis and then electro-transferred to polyvinylidene difluoride (PVDF) membranes (Millipore, Bedford, MA, USA), blotted with each antibody and detected using an ECL kit (Amersham Pharmacia Biotech, Piscataway, NJ, USA).

Transfection with siRNA. The 25-nucleotide small interfering RNA (siRNA) duplexes used in this study were purchased from Invitrogen and had the following sequences: DR5, AUC AGC AUC GUG UAC AAG GUG UCC C; the scrambled control, AAG ACC CGC GCC GAG GUG AAG. HT-29 cells were plated in each well of 6-well plates and allowed to adhere for $24 \mathrm{~h}$. On the day of transfection, $12 \mu \mathrm{l}$ of Lipofectamine 2000 (Invitrogen) was added to $50 \mathrm{nmol} / 1$ siRNA in a final volume of $100 \mu \mathrm{l}$ of culture medium. After $48 \mathrm{~h}$ of transfection, cells were treated with casticin for $12 \mathrm{~h}$ and then exposed to TRAIL for $24 \mathrm{~h}$.

Statistical analysis. Data are presented as the means \pm standard deviation (SD) unless otherwise indicated. Differences between groups were analyzed using one-way analysis of variance (ANOVA) or t-test when appropriate. All the statistical analyses were performed with the SPSS 15.0 software package (SPSS Inc., Chicago, IL, USA). P $<0.05$ was considered to indicate statistically significant differences.

\section{Results}

Casticin enhances TRAIL-induced apoptosis in HT-29 cells. The cytotoxicity of TRAIL or casticin in HT-29 cells was determined by MTT assay. TRAIL or casticin alone inhibited the proliferation of HT-29 cells in a concentration-dependent manner, and their $\mathrm{IC}_{50}$ values were $19.9 \mu \mathrm{mol} / \mathrm{l}$ and $318 \mathrm{ng} / \mathrm{ml}$, respectively. Only a slight cytotoxic activity was observed when the cells were treated with TRAIL at $25-50 \mathrm{ng} / \mathrm{ml}$ or casticin at 1.0-3.0 $\mu \mathrm{mol} / 1$ for $24 \mathrm{~h}$. However, combined treatment with TRAIL and casticin at the above subtoxic concentrations resulted in marked cytotoxicity compared with TRAIL or casticin alone, suggesting that casticin enhances TRAIL-induced cytotoxicity in HT-29 cells.

Apoptosis was determined by morphological observation and flow cytometric analysis. Our observation using AO/EB staining showed that casticin ( 1 and $3 \mu \mathrm{mol} / 1)$ or TRAIL (50 $\mathrm{ng} / \mathrm{ml}$ ) alone induced $\sim 10 \%$ apoptosis in HT-29 cell. However, the combination treatment with casticin and TRAIL enhanced apoptosis to $52.9 \pm 6.9 \%$ (Fig. 1A). Flow cytometric analysis also showed that casticin potentiated TRAIL-induced 
A

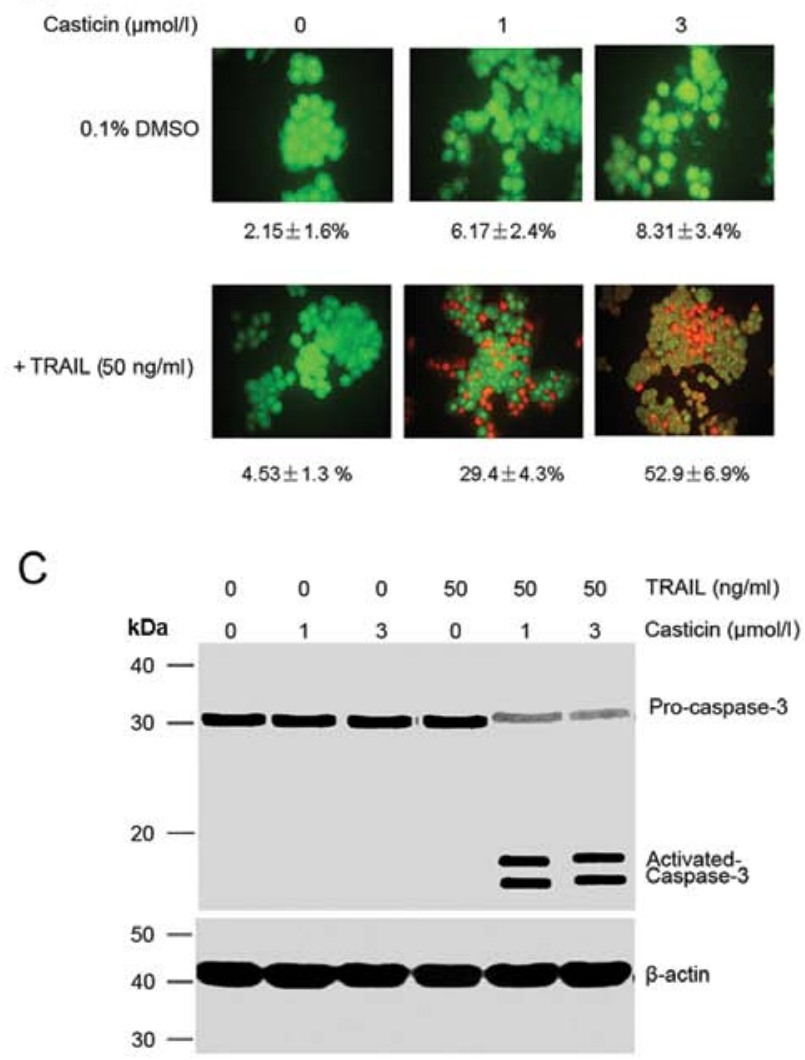

B
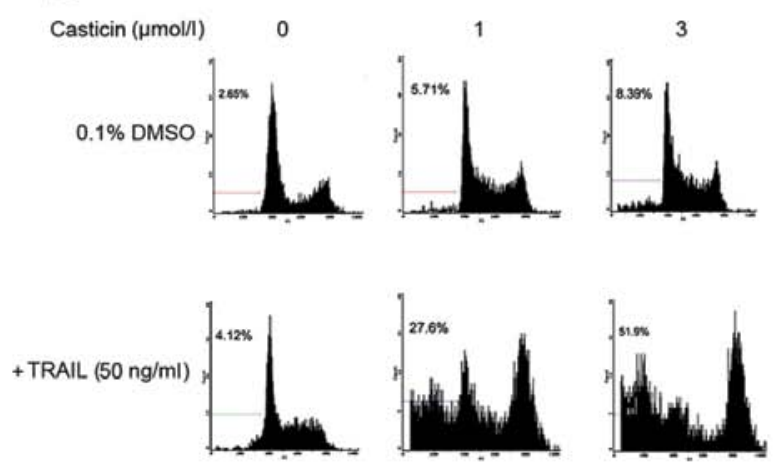

Figure 1. Casticin enhanced TRAIL-induced apoptosis in HT-29 cells. Cells were treated with the indicated concentrations of casticin (0, 1 and $3 \mu$ mol/1) for $12 \mathrm{~h}$ and then rinsed with PBS. Thereafter, cells were treated with TRAIL (50 ng/ml) or not for $24 \mathrm{~h}$. (A) Cells were stained with AO/EB and apoptotic cells were determined. Data are presented as the means \pm SD. (B) Cells were stained with PI and apoptosis was analyzed as the sub-G1 fraction by flow cytometry. $(\mathrm{C}$ and $\mathrm{D})$ Whole-cell extracts were prepared and analyzed by western blotting using antibodies against caspase-3 and PARP. $\beta$-actin was used as an internal control to show equal loading of proteins.

apoptosis, from $6.1 \pm 3.7$ and $5.38 \pm 3.3 \%$ with casticin $(3 \mu \mathrm{mol} / \mathrm{l})$ and TRAIL (50 ng/ml) alone, respectively, to $53.8 \pm 6.9 \%$ when used in combination (Fig. 1B).

Next, we examined the effect of casticin, TRAIL and their combination on the activation of caspase-3 and PARP cleavage, and found that casticin or TRAIL alone had little effect on the activation of caspase- 3 and PARP cleavage, but the combined treatment was highly effective (Fig. 1C and D), which further demonstrates that casticin enhances TRAILinduced apoptosis.

Casticin downregulates the expression of cell survival proteins in HT-29 cells. Numerous anti-apoptotic proteins are involved in resistance to TRAIL-induced apoptosis (22-25). The effect of casticin on the expressions of these anti-apoptotic proteins was examined. HT-29 cells were exposed to different concentrations of casticin for $24 \mathrm{~h}$, and the expressions of Bcl-xL, Bcl-2, survivin, XIAP, cFLIP, cIAP-1 and TRAF1 were analyzed by western blotting. Casticin inhibited the expressions of Bcl-xL, Bcl-2, survivin, XIAP, cFLIP, but had no effect on the expressions of cIAP-1 and TRAF1 (Fig. 2A).

In addition, the effect of casticin on the expressions of proapoptotic proteins was also examined. Casticin upregulated the expression of Bax and caused the cleavage of Bid protein in a dose-dependent manner (Fig. 2B). The above results suggest that downregulation of anti-apoptotic proteins and upregula- tion of pro-apoptotic proteins may be the mechanism by which casticin potentiates TRAIL-induced apoptosis.

Casticin induces the expression of DR5 in colon cancer cells. The effect of casticin on the expressions of TRAIL receptors was examined with western blotting or flow cytometry. Casticin increased the expression of DR5, but had no effect on the expressions of DR4, DcR1 and DcR2 in HT-29 cells. Furthermore, casticin increased the expression of DR5 in a dose-and time-dependent manner (Fig. 3A-C).

To investigate whether the upregulation of DR5 by casticin was specific to HCT-116 or whether it also occurs in other cell types, we examined the expression of DR5 in SW480 and HCT-116 after treatment with casticin. Casticin induced the expression of DR5 in both cell types (Fig. 3D).

DR5 induction is required for the enhancement of TRAILinduced apoptosis by casticin in HT-29 cells. To determine the role of DR5 in TRAIL-induced apoptosis, we used siRNA specific to DR5 to downregulate its expression in HT-29 cells. Transfection of cells with siRNA for DR5 but not with the control siRNA reduced casticin-induced DR5 expression. DR5 siRNA had a minimal effect on the expression of DR4 (Fig. 4A).

Subsequently, the effect of DR5 siRNA on the enhancement of TRAIL-induced apoptosis by casticin was examined using 
A

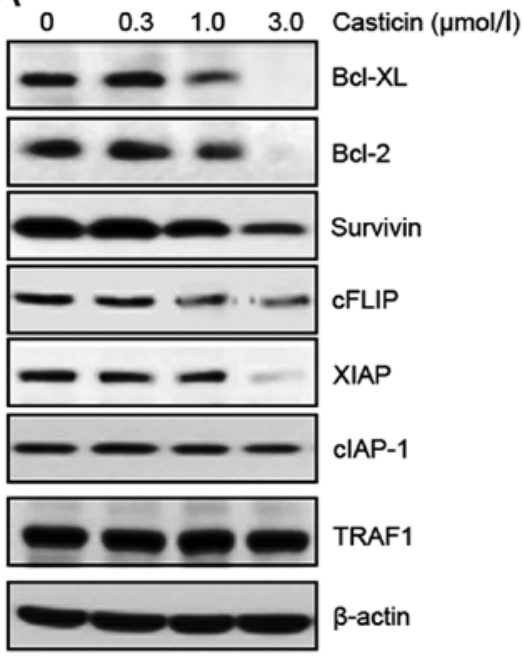

B

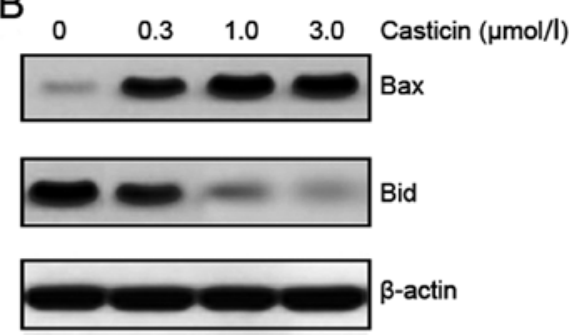

Figure 2. Effect of casticin on the expression of the anti-apoptotic and pro-apoptotic proteins. HT-29 cells were treated with the indicated concentrations of casticin $(0,0.3,1$ and $3 \mu \mathrm{mol} / \mathrm{l})$ for $24 \mathrm{~h}$, and then whole-cell extracts were prepared and analyzed by western blotting using the indicated antibodies to detect anti-apoptotic (A) and pro-apoptotic proteins. (B) $\beta$-actin was used as an internal control to show equal loading of proteins.
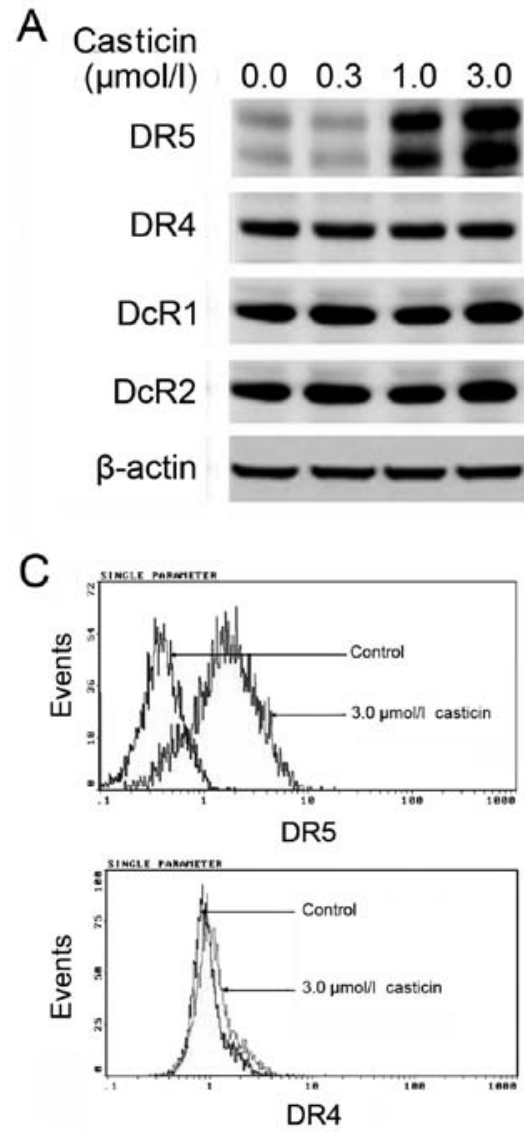

\section{B Treatment of} $3.0 \mu \mathrm{mol} / \mathrm{l}(\mathrm{time})$
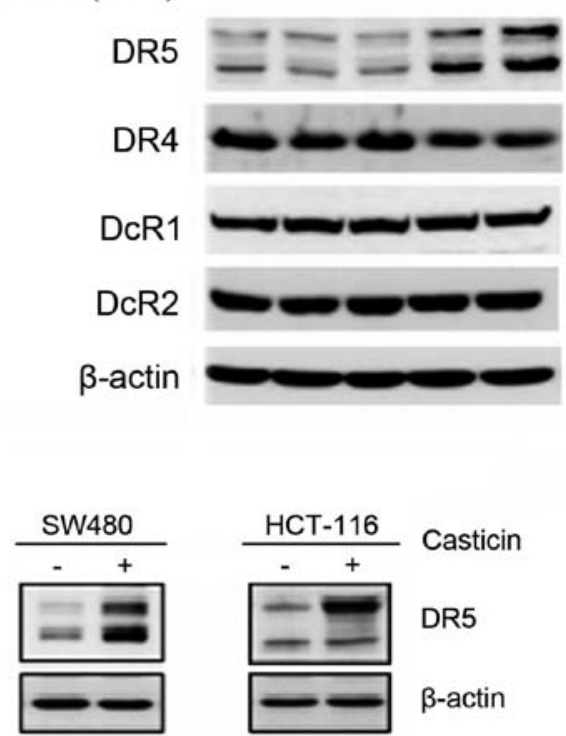

Figure 3. Effect of casticin on the expression of TRAIL receptors. (A) HT-29 cells were treated with the indicated concentrations of casticin ( $0,0.3,1$ and $3 \mu \mathrm{mol} / \mathrm{l})$ for $24 \mathrm{~h}$. (B) HT-29 cells were treated with casticin ( $3 \mu \mathrm{mol} / \mathrm{l})$ for the indicated time periods $(0,3,6,12$ and $24 \mathrm{~h})$. Whole-cell extracts were then prepared and western blotting was used to analyze the extracts for TRAIL receptor expressions. (C) HT-29 cells were treated with casticin (0 or $3 \mu \mathrm{mol} / \mathrm{l})$ for $24 \mathrm{~h}$, and the expressions of DR4 and DR5 were measured by flow cytometry. (D) SW480 and HCT-116 cells were treated with $3 \mu \mathrm{mol} / 1 \mathrm{casticin}$ for $24 \mathrm{~h}$ and DR5 expression was analyzed with western blotting. $\beta$-actin was used as an internal control to show equal loading of proteins.

morphological observation following AO/EB staining. Our results showed that the effect of casticin on TRAIL-induced apoptosis was effectively abolished in cells transfected with
DR5 siRNA, but treatment with control siRNA had no effect (Fig. 4B). These facts suggest that DR5 plays a critical role in the enhancement of TRAIL-induced apoptosis by casticin. 
A

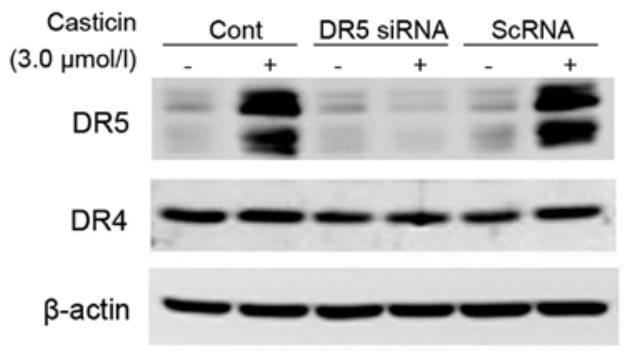

B

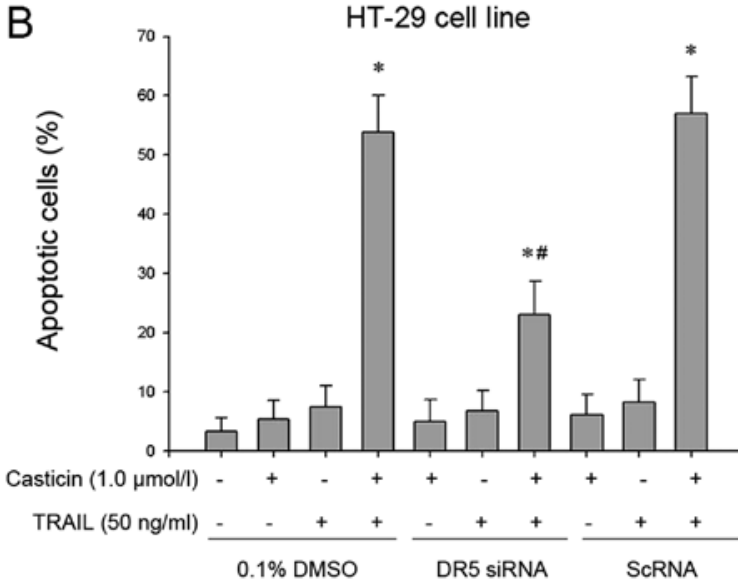

Figure 4. Effect of knockdown of DR5 on casticin-induced sensitization of TRAIL in HT-29 cells. Cells were transfected with DR5 siRNA or control siRNA for $24 \mathrm{~h}$. (A) After siRNA transfection, cells were treated with $3 \mu \mathrm{mol} / 1$ casticin for $24 \mathrm{~h}$, and whole-cell extracts were subjected to western blotting for DR5 and DR4. $\beta$-actin was used as an internal control to show equal loading of proteins. (B) After siRNA transfection, cells were pretreated with 0 or $1 \mu$ mol/l casticin for $12 \mathrm{~h}$ and rinsed with PBS. Thereafter, the cells were treated with TRAIL ( $50 \mathrm{ng} / \mathrm{ml}$ ) or not for $24 \mathrm{~h}$, and apoptosis was determined using morphological observation after AO/EB staining. ${ }^{*} \mathrm{P}<0.05$ compared with cells treated with casticin or TRAIL alone, ${ }^{\#} \mathrm{P}<0.05$ compared with corresponding untransfected cells or cells transfected with control siRNA.

A

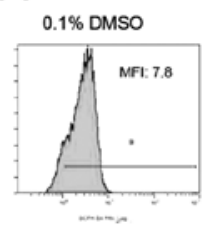

1.0 moll casticin

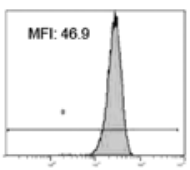

B

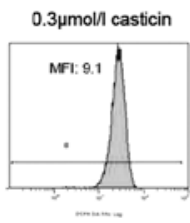

$3.0 \mu \mathrm{mol} / \mathrm{l}$ casticin

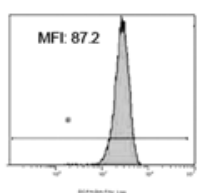

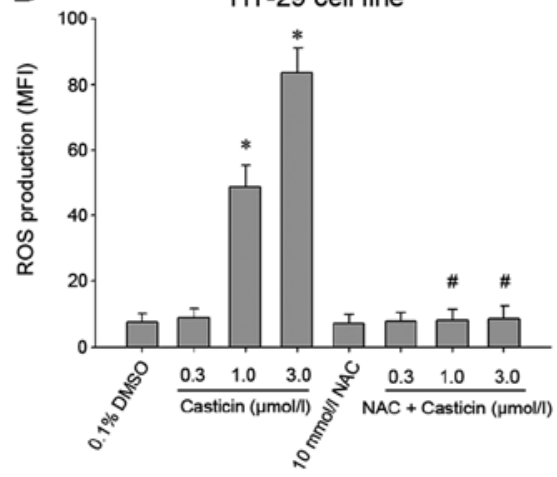

C

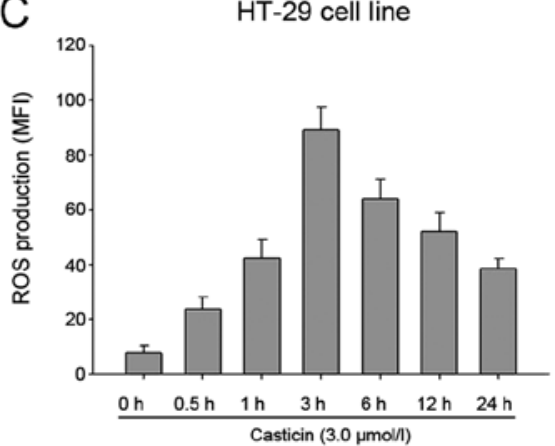

HT-29 cell line

$\mathrm{D}$

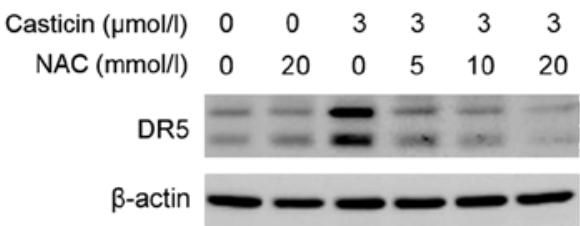

Figure 5. Casticin induces ROS generation, and upregulation of DR5 and potentiation of TRAIL-induced apoptosis by casticin are mediated by ROS in HT-29 cells. (A) Cells were treated with the indicated concentrations of casticin ( $0,0.3,1$ and $3 \mu \mathrm{mol} / 1)$ for $24 \mathrm{~h}$. ROS were measured by flow cytometry and quantified using the mean fluorescence intensity (MFI). (B) Cells were pretreated with $\mathrm{N}$-acetylcysteine (10 mmol/l) for $1 \mathrm{~h}$, and then treated with the indicated concentrations of casticin $(0,0.3,1$ and $3 \mu \mathrm{mol} / 1)$ for $24 \mathrm{~h}$. ROS were measured by flow cytometry. (C) Cells were treated with casticin ( $3 \mu \mathrm{mol} / \mathrm{l})$ for the indicated time periods ( $0-24 \mathrm{~h}$ ) and ROS were measured by flow cytometry. (D) Cells were pretreated with $\mathrm{N}$-acetylcysteine (10 mmol/l) for $1 \mathrm{~h}$ and then treated with casticin $(3 \mu \mathrm{mol} / \mathrm{l})$ for $24 \mathrm{~h}$. Whole-cell extracts were subjected to western blotting for DR5. $\beta$-actin was used as an internal control to show equal loading of proteins. (E) Cells were pretreated with $\mathrm{N}$-acetylcysteine $(0$ or $10 \mathrm{mmol} / \mathrm{l})$ for $1 \mathrm{~h}$ and then treated with casticin $(0$ or $3 \mu \mathrm{mol} / \mathrm{l})$ for $12 \mathrm{~h}$. Thereafter, the cells were rinsed with PBS and treated with TRAIL $(50 \mathrm{ng} / \mathrm{ml})$ or not for $24 \mathrm{~h}$. Apoptosis was determined using morphological observation after AO/EB staining. ${ }^{*} \mathrm{P}<0.05$ compared with control cells, ${ }^{\text {"}} \mathrm{P}<0.05$ compared with corresponding cells without treatment of $\mathrm{N}$-acetylcysteine.

DR5 induction and enhancement of TRAIL-induced apoptosis by casticin are ROS-dependent in HT-29 cells. Numerous studies have shown that ROS are implicated in
TRAIL receptor induction $(8,26,27)$. Therefore, we investigated whether casticin mediates its effects through ROS. Intracellular ROS was measured by flow cytometry using 
the fluorescent probe DCFH-DA, and the results showed that casticin induced ROS generation in a dose-dependent manner (Fig. 5A and B). Furthermore, ROS levels increased initially at $0.5 \mathrm{~h}$, reached the peak at $3 \mathrm{~h}$ and persisted for up to $24 \mathrm{~h}$ after treatment with $3.0 \mu \mathrm{M}$ casticin (Fig. 5C). Next, the effect of ROS on casticin-induced DR5 was examined. We found that pretreatment of cells with $\mathrm{N}$-acetylcysteine reduced the casticin-induced upregulation of DR5 expression (Fig. 5D). In addition, we investigated the effect of ROS on the potentiation of TRAIL-induced apoptosis by casticin. As shown in Fig. 5E, pretreatment with $\mathrm{N}$-acetylcysteine markedly reduced the enhancement of TRAIL-induced apoptosis by casticin in HT-29 cells from $54.2 \pm 8.4$ to $18.7 \pm 5.3 \%$. The above findings suggest that ROS play a critical role in mediating the effects of casticin on DR5 expression and TRAIL-induced apoptosis.

\section{Discussion}

TRAIL is a potential anticancer agent that can selectively induce apoptosis in a wide variety of cancer cells (1). However, resistance of cancer cells to TRAIL-induced apoptosis limits its therapeutic application. Recent studies have shown that several chemotherapeutic drugs, i.e., curcumin, garcinol, gossypol, kaempferol, can modulate TRAIL-induced apoptosis in cancer cells (8-11), suggesting that TRAIL resistance can be overcome by combination treatment, which may be a new strategy for cancer therapy. Casticin, a flavonoid isolated from Vitex rotundifolia, has been demonstrated to have antitumor activities (i.e., inhibition of proliferation, induction of apoptosis) against breast, lung, liver and colon cancer, and leukemia $(15-17,20)$. In the present study, we found that casticin enhances TRAIL-induced apoptosis in colon cancer cells, and the mechanisms involve downregulation of cell survival proteins and upregulation of DR5.

Bcl-2 family proteins are central regulators of apoptosis and act primarily on the mitochondria. On the basis of the structural and functional characteristics, they are divided into anti-apoptotic and pro-apoptotic proteins. The former have 4 Bcl-2 homology domains (BH1, -2, -3 and -4) and include Bcl-2, Bcl-xL, Mcl-1, Bcl-w and A1/Bfl-1 and the latter include Bax, Bak, and Box that contain 3 BH domains (BH1, -2 and -3) and Bid, Bim and Bad that contain only the $\mathrm{BH} 3$ domain (28). Several studies have shown that Bcl-2 and Bcl-xL are involved in TRAIL resistance in tumor cells $(22,23)$. In the present study, we found that casticin inhibits the expressions of Bcl-xL and Bcl-2; furthermore, casticin upregulates the expression of Bax and causes the cleavage of Bid protein in a dose-dependent manner, which may be one of its mechanisms of potentiation of TRAIL-induced apoptosis.

Inhibitors of apoptosis (IAPs) are a family of anti-apoptotic proteins that bind and inhibit caspases-3, -7 and -9 , but not caspase-8, thereby inhibiting their activation and preventing apoptosis. Eight IAPs have been identified thus far, including survivin, X-chromosome-linked IAP (XIAP), cellular IAP1 (c-IAP1), and c-IAP2 (29). Survivin and XIAP have also been shown to be associated with tumor cell resistance to TRAIL. Azuhata et al reported that survivin can inhibit apoptosis induced by TRAIL, and that inhibiting survivin expression by antisense oligonucleotides enhances TRAIL sensitivity in human NB cells (24). Overexpression of XIAP is shown to confer resistance against TRAIL in cancer cells (22). Furthermore, Siegelin et al have shown that the XIAP inhibitor Embelin enhances TRAIL-mediated apoptosis in malignant glioma cells, and its mechanism involves downregulation of the short isoform of FLIP (25). FLICE (FADD-like IL-1 $\beta$-converting enzyme) inhibitory protein (FLIP) is a critical anti-apoptotic regulator that inhibits TNF- $\alpha$, Fas-L and TRAIL-induced apoptosis as well as chemotherapy-triggered apoptosis in malignant cells. Three isoforms of human cytosolic FLIP (c-FLIP) have been identified, long (c-FLIPL), short (c-FLIPS) and c-FLIPR. c-FLIP binds to FADD and/ or caspase- 8 or -10 in a ligand-dependent and-independent fashion, thereby preventing the activation of procaspase- 8 (30). In the present study, we found that casticin inhibits the expressions of survivin, XIAP and cFLIP, but has no effect on the expressions of cIAP-1 and TRAF1 [tumor necrosis factor receptor-associated factor 1 , thought to be a regulator of cell death and cellular responses to stress (31)]. Inhibition of survivin, XIAP and cFLIP may also be one of the mechanisms of potentiation of TRAIL-induced apoptosis by casticin.

Disregulation of TRAIL receptors is involved in TRAIL resistance in tumor cells $(6,7)$. Five TRAIL receptors have been discovered so far, including DR4, DR5, DcR1, DcR2 and osteoprotegerin. DR4 and DR5 contain a cytoplasmic region designated 'death domain' (DD) that transduces the death signal. However, DcR1 and DcR2 lack a functional death domain and cannot transduce a pro-apoptotic signal; instead, they compete with DR4 and DR5 for TRAIL binding, and inhibit DR4- and DR5-mediated apoptosis by TRAIL $(2,3)$. In the present study, we found that casticin increases the expression of DR5 in a dose-and time-dependent manner, but it has no effect on the expressions of DR4, DcR1 and DcR2 in colon cancer cells. Consistent with our study, casticin has been shown to upregulate DR5 in hepatocellular carcinoma cells (18). In addition, we found that DR5 upregulation is critical for the enhancement of TRAIL-induced apoptosis by casticin, which is evidenced by the fact that gene silencing of DR5 abolished the effect of casticin on TRAIL-induced apoptosis.

Reactive oxygen species (ROS) are chemically reactive molecules containing oxygen, including oxygen ions $\left(\mathrm{O}_{2}{ }^{\circ}\right)$, hydrogen peroxide $\left(\mathrm{H}_{2} \mathrm{O}_{2}\right)$, and play an important role in a variety of physiological and pathological processes. Kwon et al showed that $\mathrm{H}_{2} \mathrm{O}_{2}$ can upregulate the expression of DR5, thereby enhancing TRAIL-induced cell death in human astrocytic cells (26). There are several chemotherapeutic agents that induce DR5 through ROS dependent pathways and sensitize TRAIL induced-apoptosis, including curcumin, zerumbone, sulforaphane $(8,26,32)$, demonstrating that ROS play a major role in the modulation of DR5. In the present study, we found that casticin induces ROS generation in a dose-dependent manner in colon cancer cells, which, however, is in contrast to another report that casticin has no effect on intracellular ROS in hepatocellular carcinoma cells (18). The explanation for this discrepancy may be due to different cell types. Similar to those previous studies, our study also showed that ROS play a critical role in mediating the effects of casticin on DR5 expression and TRAIL-induced apoptosis, as evidenced by the fact that quenching of ROS by N-acetylcysteine abolished the above effects. 
In summary, the present study demonstrated that casticin can enhance TRAIL-induced apoptosis through downregulation of cell survival proteins (Bcl-xL, Bcl-2, survivin, XIAP and cFLIP) and induction of DR5 mediated by ROS. Casticin is a potential chemotherapeutic agent that can overcome TRAIL resistance when used in combination with TRAIL; therefore, further studies are warranted, particularly in clinical trials.

\section{Acknowledgements}

This study was supported by grants from the Project Item of Scientific Research of the Administration Bureau of Traditional Chinese Medicine of Hunan Province (no. 2010081), the Project Item of Scientific Research of the Department of Education of Hunan Province (no. 10C0975), and the Major Project Item of Scientific Research of the Department of Education of Hunan Province (no. 09A054).

\section{References}

1. MacFarlane M: TRAIL-induced signalling and apoptosis. Toxicol Lett 139: 89-97, 2003.

2. Pan G, Ni J, Wei YF, Yu G, Gentz R and Dixit VM: An antagonist decoy receptor and a death domain-containing receptor for TRAIL. Science 277: 815-818, 1997.

3. Emery JG, McDonnell P, Burke MB, et al: Osteoprotegerin is a receptor for the cytotoxic ligand TRAIL. J Biol Chem 273 14363-14367, 1998.

4. Mellier G, Huang S, Shenoy K and Pervaiz S: TRAILing death in cancer. Mol Aspects Med 31: 93-112, 2010.

5. Zhang L and Fang B: Mechanisms of resistance to TRAILinduced apoptosis in cancer. Cancer Gene Ther 12: 228-237, 2005

6. Rieger J, Frank B, Weller M and Wick W: Mechanisms of resistance of human glioma cells to Apo2 ligand/TNF-related apoptosis-inducing ligand. Cell Physiol Biochem 20: 23-34, 2007.

7. Kurbanov BM, Fecker LF, Geilen CC, Sterry W and Eberle J: Resistance of melanoma cells to TRAIL does not result from upregulation of antiapoptotic proteins by NF-kappaB but is related to downregulation of initiator caspases and DR4 Oncogene 26: 3364-3377, 2007.

8. Jung EM, Lim JH, Lee TJ, Park JW, Choi KS and Kwon TK: Curcumin sensitizes tumor necrosis factor-related apoptosisinducing ligand (TRAIL)-induced apoptosis through reactive oxygen species-mediated upregulation of death receptor 5 (DR5). Carcinogenesis 26: 1905-1913, 2005.

9. Prasad S, Ravindran J, Sung B, Pandey MK and Aggarwal BB: Garcinol potentiates TRAIL-induced apoptosis through modulation of death receptors and antiapoptotic proteins. Mol Cancer Ther 9: 856-868, 2010.

10. Sung B, Ravindran J, Prasad S, Pandey MK and Aggarwal BB: Gossypol induces death receptor-5 through activation of the ROS-ERK-CHOP pathway and sensitizes colon cancer cells to TRAIL. J Biol Chem 285: 35418-35427, 2010.

11. Siegelin MD, Reuss DE, Habel A, Herold-Mende C and von Deimling A: The flavonoid kaempferol sensitizes human glioma cells to TRAIL-mediated apoptosis by proteasomal degradation of survivin. Mol Cancer Ther 7: 3566-3574, 2008.

12. Koh DJ, Ahn HS, Chung HS, et al: Inhibitory effects of casticin on migration of eosinophil and expression of chemokines and adhesion molecules in A549 lung epithelial cells via NF-kappaB inactivation. J Ethnopharmacol 136: 399-405, 2011.

13. Choudhary MI, Jalil S, Nawaz SA, Khan KM and Tareen RB: Antiinflammatory and lipoxygenase inhibitory compounds from Vitex agnus-castus. Phytother Res 23: 1336-1339, 2009.
14. Mesaik MA, Murad S, Khan KM, Tareen RB, Ahmed A and Choudhary MI: Isolation and immunomodulatory properties of a flavonoid, casticin from Vitex agnus-castus. Phytother Res 23: $1516-1520,2009$

15. Csupor-Loffler B, Hajdu Z,Zupko I, et al: Antiproliferative effect of flavonoids and sesquiterpenoids from Achillea millefolium s.1. on cultured human tumour cell lines. Phytother Res 23: 672-676, 2009.

16. Haidara K, Zamir L, Shi QW and Batist G: The flavonoid Casticin has multiple mechanisms of tumor cytotoxicity action. Cancer Lett 242: 180-190, 2006.

17. Kobayakawa J, Sato-Nishimori F, Moriyasu M and Matsukawa Y: G2-M arrest and antimitotic activity mediated by casticin, a flavonoid isolated from Viticis Fructus (Vitex rotundifolia Linne file). Cancer Lett 208: 59-64, 2004.

18. Shen JK, Du HP, Yang M, Wang YG and Jin J: Casticin induces leukemic cell death through apoptosis and mitotic catastrophe. Ann Hematol 88: 743-752, 2009.

19. Yang J, Yang Y, Tian L, Sheng XF, Liu F and Cao JG: Casticininduced apoptosis involves death receptor 5 upregulation in hepatocellular carcinoma cells. World J Gastroenterol 17: 4298-4307, 2011

20. Cao JG, Peng SP, Sun L, Li H, Wang L and Deng HW: Vascular basement membrane-derived multifunctional peptide, a novel inhibitor of angiogenesis and tumor growth. Acta Biochim Biophys Sin 38: 514-521, 2006.

21. Yang XH, Zheng X, Cao JG, Xiang HL, Liu F and Lv Y: 8-Bromo-7-methoxychrysin-induced apoptosis of hepatocellular carcinoma cells involves ROS and JNK. World J Gastroenterol 16: 3385-3393, 2010

22. Fulda S, Meyer E and Debatin KM: Inhibition of TRAIL-induced apoptosis by Bcl-2 overexpression. Oncogene 21: 2283-2294, 2002.

23. Song JJ, An JY, Kwon YT and Lee YJ: Evidence for two modes of development of acquired tumor necrosis factor-related apoptosisinducing ligand resistance. Involvement of Bcl-xL. J Biol Chem 282: 319-328, 2007.

24. Azuhata T, Scott D, Griffith TS, Miller M and Sandler AD: Survivin inhibits apoptosis induced by TRAIL, and the ratio between survivin and TRAIL receptors is predictive of recurrent disease in neuroblastoma. J Pediatr Surg 41: 1431-1440, 2006.

25. Siegelin MD, Gaiser T and Siegelin Y: The XIAP inhibitor Embelin enhances TRAIL-mediated apoptosis in malignant glioma cells by down-regulation of the short isoform of FLIP. Neurochem Int 55: 423-430, 2009.

26. Kwon D, Choi K, Choi C and Benveniste EN: Hydrogen peroxide enhances TRAIL-induced cell death through up-regulation of DR5 in human astrocytic cells. Biochem Biophys Res Commun 372: 870-874, 2008.

27. Yodkeeree S, Sung B, Limtrakul P and Aggarwal BB: Zerumbone enhances TRAIL-induced apoptosis through the induction of death receptors in human colon cancer cells: evidence for an essential role of reactive oxygen species. Cancer Res 69: 6581-6589, 2009

28. Ola MS, Nawaz M and Ahsan $\mathrm{H}$ : Role of Bcl-2 family proteins and caspases in the regulation of apoptosis. Mol Cell Biochem 351: 41-58, 2011

29. Altieri DC: Survivin and IAP proteins in cell-death mechanisms. Biochem J 430: 199-205, 2010.

30. Safa AR and Pollok KE: Targeting the anti-apoptotic protein c-FLIP for cancer therapy. Cancers 3: 1639-1671, 2011.

31. Bradley JR and Pober JS: Tumor necrosis factor receptor-associated factors (TRAFs). Oncogene 20: 6482-6491, 2001.

32. Kim H, Kim EH, Eom YW, et al: Sulforaphane sensitizes tumor necrosis factor-related apoptosis-inducing ligand (TRAIL)resistant hepatoma cells to TRAIL-induced apoptosis through reactive oxygen species-mediated up-regulation of DR5. Cancer Res 66: 1740-1750, 2006. 